\title{
A COMPARATIVE STUDY BETWEEN 0.5\% BUPIVACAINE WITH CLONIDINE AND 0.5\% BUPIVACAINE FOR SUPRACLAVICULAR BRACHIAL PLEXUS BLOCK IN UPPER LIMB SURGERIES
}

\author{
Vijayanand Siddalingappaㄹ, Nayana Jayanna² \\ ${ }^{1}$ Associate Professor, Department of Anaesthesiology, Kempegowda Institute of Medical Sciences, Bengaluru. \\ 2Postgraduate, Department of Anaesthesiology, Kempegowda Institute of Medical Sciences, Bengaluru.
}

\begin{tabular}{l}
\hline ABSTRACT \\
\hline BACKGROUND \\
Supraclavicular brachial plexus block provides safe, effective, low cost anaesthesia with excellent post-operative analgesia. The \\
current study was an attempt to compare Bupivacaine $0.5 \%$ with Bupivacaine $0.5 \%$ plus clonidine $2 \mu \mathrm{g} / \mathrm{kg}$ in supraclavicular brachial \\
plexus block with respect to onset time and duration of sensory blockade, duration of analgesia and side effects.
\end{tabular}

AIM

To evaluate whether additional anaesthetic and analgesic effects could be derived from administration of Clonidine, an $\alpha 2$ adrenergic agonist into brachial plexus sheath.

\section{METHODOLOGY}

Each patient was randomly allocated to one of the two groups of 30 patients each. Bupivacaine Group (B): Receives $30 \mathrm{~mL}$ Bupivacaine $0.5 \%$ and $1 \mathrm{~mL}$ of normal saline. Bupivacaine plus Clonidine Group(C): Receives $30 \mathrm{~mL}$ Bupivacaine 0.5\% and clonidine $2 \mu \mathrm{g} / \mathrm{kg}$ in $1 \mathrm{~mL}$ saline. The effect was studied with respect to Onset time and Duration of Sensory and Motor blockade, Duration of Analgesia and Side effects.

\section{RESULTS}

In our study, we observed that onset of sensory block was earlier in Bupivacaine plus Clonidine group (Group C) having a mean value 7.20 \pm 1.95 minutes in comparison with Bupivacaine group (Group B) having a mean value of $17.63 \pm 3.25$ minutes, which is statistically significant.

\section{KEYWORDS}

Clonidine, Supraclavicular Brachial Plexus Block, 0.5\% Bupivacaine.

HOW TO CITE THIS ARTICLE: Siddalingappa V, Jayanna N. A comparative study between 0.5\% bupivacaine with clonidine and $0.5 \%$ bupivacaine for supraclavicular brachial plexus block in upper limb surgeries. J. Evolution Med. Dent. Sci. 2016;5(76):5650-5653, DOI: $10.14260 /$ jemds/2016/1274

\section{INTRODUCTION}

Peripheral nerve blockade is now a well-accepted concept for comprehensive anaesthetic care. It has become important in clinical practice, because of their role in post-operative pain relief, shortening of patient recovery time and avoiding risks and adverse effects of General anaesthesia.

Supraclavicular brachial plexus block is the preferred regional anaesthesia for upper limb surgeries. Here, the brachial plexus is presented most compactly at the proximal division or at the trunk level that provides most reliable anaesthesia for upper limb surgeries by anaesthetising the middle and lower plexus over $80 \%$ of the times (median, radial and ulnar).

Local anaesthetics administered as regional nerve blocks provides postoperative pain relief by blocking signal transmission to dorsal horn. Synthesis of Lignocaine in 1943 by Lofgren's laid foundation for the studies of amide local

Financial or Other, Competing Interest: None.

Submission 12-05-2016, Peer Review 09-09-2016,

Acceptance 15-09-2016, Published 22-09-2016.

Corresponding Author:

Dr. Vijayanand Siddalingappa,

\#27/36, 10 C Main Road,

Next to PTA School,

1 st Block, Jayanagar,

Bengaluru-560011.

E-mail:dr.vanand@rediffmail.com

DOI: $10.14260 /$ jemds/2016/1274 anaesthetics. From these studies have come derivatives of Lignocaine such as Mepivacaine, Prilocaine, Bupivacaine and Etidocaine.

Bupivacaine is a long-acting local anaesthetic. Due to its long duration of action and combined with its high quality sensory blockade compared to motor blockade, it has been the most commonly used local anaesthetic for peripheral nerve blocks.

Certain drugs may be used as adjuncts to local anaesthetics to lower the dose of each agent, to enhance onset, duration of action and analgesic efficacy.

Several studies have demonstrated analgesic effects of "Clonidine," an alpha agonist, in local, spinal and epidural anaesthesia when combined with local anaesthetics. This observation that Clonidine has analgesic effects at spinal level has stimulated research to examine analgesic effects in the periphery. It has direct local action on the nerve itself and facilitation of local anaesthetic action. Also, Clonidine seems to provide analgesic benefit without major adverse effects.

The aim of this study is to evaluate whether additional anaesthetic and analgesic effects could be derived from administration of Clonidine, an $\alpha 2$-adrenergic agonist into brachial plexus sheath.

\section{AIMS AND OBJECTIVES}

The present study was a prospective study at Kempegowda Institute of Medical Sciences, Bangalore in the Department of Anaesthesiology with the objective to compare the effect of 
Bupivacaine $0.5 \%$ plus clonidine $2 \mu \mathrm{g} / \mathrm{kg}$ and Bupivacaine $0.5 \%$ used for Supraclavicular approach to brachial plexus block with respect to,

- Onset time of sensory block.

- Onset time of motor block.

- Duration of sensory block.

- Duration of motor block.

- Duration of analgesia.

\section{MATERIALS AND METHODS}

\section{Source of Data}

The present study was a prospective study carried out at Kempegowda Institute of Medical Sciences, Bangalore, in the Department of Anaesthesiology entitled "A comparative study between $0.5 \%$ bupivacaine with clonidine and $0.5 \%$ bupivacaine for supraclavicular brachial plexus block in upper limb surgeries" from December 2012 to July 2014.

Sample Design: Randomised clinical trial.

Sample Size: 30 subjects in each group.

Sampling Method: Simple Random Sampling.

Statistical Analysis: Student's t-test and repeated measures of ANOVA for vital events.

\section{METHODS OF COLLECTION OF DATA}

Sixty patients aged between 18 years and 60 years of physical status ASA grade 1 and ASA grade 2 undergoing elective upper limb surgeries lasting more than 30 minutes was included in the study after Ethical Clearance from the College Ethical Committee. Each patient was visited pre-operatively and procedure explained and written and informed consent to be obtained, Complete blood count, Blood grouping. Blood sugars, Bleeding time, Clotting time, Blood urea, Serum electrolytes, chest X-ray, ECG were done. All the patients pre-medicated with tablet alprazolam $0.5 \mathrm{mg}$ overnight and morning of surgery.

\section{Inclusion Criteria}

- Patients aged between 18 years and 60 years.

- Patients with ASA grade 1 and ASA grade 2.

- Weighing $>50 \mathrm{~kg}$ and $<80 \mathrm{~kg}$.

- Scheduled for upper limb surgeries.

\section{Exclusion Criteria}

- Patients other than ASA grade 1 and 2.

- Local infection at the site of block.

- Known allergic to local anaesthetic agents and alpha 2 agonist agents.

- Brachial plexus injury.

- Bleeding disorders or patient on anticoagulant therapy.

- Pregnant women.

- History of cardiovascular diseases.

- Neuromuscular disorders.

- Hepatic or renal failure.

\section{Study Group}

Each patient was randomly selected and divided into two groups of thirty patients each:

Group B - Receives $30 \mathrm{~mL}$ of Bupivacaine $0.5 \%$ and $1 \mathrm{~mL}$ of normal saline.
Group C - Receives $30 \mathrm{~mL}$ of Bupivacaine $0.5 \%$ and Clonidine $2 \mu \mathrm{g} / \mathrm{kg}$ in $1 \mathrm{~mL}$.

\section{PROCEDURE}

Standard multi-parameters monitor (ECG, pulse oximeter, Noninvasive blood pressure) connected and monitored in all the patients and recorded at interval of 5 mins. for the first 30 mins. and for every 15 mins. thereafter. Patient placed in supine position with the head turned away from the side to be blocked. Supraclavicular area aseptically prepared and draped. A 23-gauge needle inserted behind the subclavian artery at $1.5 \mathrm{cms}$ above and lateral to the mid-clavicular line in backward-inward-downward direction till paraesthesia in the forearm is elicited. After negative aspiration for blood and air, $31 \mathrm{~mL}$ of $0.5 \%$ bupivacaine with Clonidine is injected to patients of Group C and $31 \mathrm{~mL}$ of $0.5 \%$ bupivacaine is injected to patients of group B.

Sensory block assessed by pin prick with 23-g hypodermic needle in skin dermatomes C5-T1 once in every 2 minutes till sensory block achieved and then every 30 minutes till patient regains normal sensations.

- 0 - Normal response to pin prick.

- 1 - Dull response to pin prick (onset).

- 2 - No response to pin prick (peak).

Quality of motor block will be assessed at the same intervals and graded as modified Lovett scoring

- Grade 6 - Normal.

- Grade 5 - Slightly reduced muscular force.

- Grade 4 - Pronounced reduction.

- Grade 3 - Slightly impaired mobility.

- Grade 2 - Pronounced mobility impairment.

- Grade 1 - Almost complete paralysis.

- Grade 0 - Complete paralysis.

Duration of analgesia will be assessed by visual analogue scale

- 0 - No pain.

- 10 - Worst pain.

Rescue analgesia given with Inj. Diclofenac 75 mg IM accordingly when patient complains of pain at surgical site The effect of the following parameters were observed:

\section{DEFINITIONS}

- Onset time of motor blockade - is taken from the completion of injection of study drug till the development of grade 4 motor blockade (Modified Lovett's)

- Onset time of sensory blockade is taken from the completion of injection of study drug till the patient does not feel the pin prick.

- Duration of motor blockade is taken from the completion of the injection of study drug till the patient develops complete motor recovery.

- Duration of sensory blockade - is taken from the time of injection of study drug till the patient feels pin prick.

- Duration of analgesia is taken from onset of sensory blockade till the patient c/o pain at surgical site.

- Patients were watched for Bradycardia, Convulsions, Restlessness, Disorientation, Drowsiness, Nausea, Vomiting and any other complications. 
All the values were expressed as Mean \pm Standard deviation, statistical comparison was performed by student's t-test and chi-square test.

A two tailed $p$ value of $>0.05$ was considered to be statistically not significant, a p value of $<0.05$ as statistically significant, a $\mathrm{p}$ value of $<0.01$ as statistically highly significant and a p value of $<0.001$ as statistically very highly significant.

\section{RESULTS}

The present study was conducted on 60 consenting patients aged between 18-60 years. Bupivacaine group (B) received 30 $\mathrm{mL}$ of $0.5 \%$ Bupivacaine plus $1 \mathrm{~mL}$ saline. Bupivacaine plus Clonidine group (C) received $30 \mathrm{~mL}$ of $0.5 \%$ Bupivacaine plus $2 \mu \mathrm{g} / \mathrm{kg}$ clonidine in $1 \mathrm{~mL}$ saline for Brachial plexus block by supraclavicular approach.

Samples were age matched with $\mathrm{P}=0.343$ (Table 1) and gender matched with $\mathrm{P}=0.766$ (Table 2).

The average weight was $62.43 \pm 7.93$ in Bupivacaine group and $61.90 \pm 9.11$ in Bupivacaine plus Clonidine group. The average height was $162.63 \pm 5.91$ in Bupivacaine group and $163.73 \pm 5.78$ in Bupivacaine plus Clonidine group. Overall, there was no significant difference in age, gender and anthropometric measures among the two groups (Table 3). In our study, we noticed $9 \mathrm{mmHg}$ mean decrease in SBP in Bupivacaine plus Clonidine group compared to Bupivacaine group at 25th minute after brachial plexus block, which is clinically not significant but statistically moderately significant $(\mathrm{p}=0.04)$ (Table 4) (Table 5) (Table 6)

\begin{tabular}{|c|c|c|c|c|}
\hline \multirow{2}{*}{ Age in Years } & \multicolumn{2}{|c|}{ Group B } & \multicolumn{2}{c|}{ Group C } \\
\cline { 2 - 5 } & No & \% & No & \% \\
\hline $20-30$ & 12 & 40.0 & 8 & 26.7 \\
\hline $31-40$ & 4 & 13.3 & 3 & 10.0 \\
\hline $41-50$ & 5 & 16.7 & 7 & 23.3 \\
\hline $51-60$ & 9 & 30.0 & 12 & 40.0 \\
\hline Total & $\mathbf{3 0}$ & $\mathbf{1 0 0 . 0}$ & $\mathbf{3 0}$ & $\mathbf{1 0 0 . 0}$ \\
\hline Mean \pm SD & $40.73 \pm 14.77$ & $44.23 \pm 13.58$ \\
\hline Table 1: Age Distribution of Patients Studied \\
\hline
\end{tabular}

\begin{tabular}{|c|c|c|c|c|}
\hline \multirow{2}{*}{ Gender } & \multicolumn{2}{|c|}{ Group B } & \multicolumn{2}{c|}{ Group C } \\
\cline { 2 - 5 } & No & \% & No & \% \\
\hline Female & 7 & 23.3 & 8 & 26.7 \\
\hline Male & 23 & 76.7 & 22 & 73.3 \\
\hline Total & $\mathbf{3 0}$ & $\mathbf{1 0 0 . 0}$ & $\mathbf{3 0}$ & $\mathbf{1 0 0 . 0}$ \\
\hline \multicolumn{3}{|c|}{ Table 2: Gender Distribution of Patients Studied } \\
\hline
\end{tabular}

\begin{tabular}{|l|c|c|c|}
\hline & Group B & Group C & P Value \\
\hline Height $(\mathrm{cm})$ & $162.63 \pm 5.91$ & $163.73 \pm 5.78$ & 0.469 \\
\hline Weight $(\mathrm{kg})$ & $62.43 \pm 7.93$ & $61.90 \pm 9.11$ & 0.810 \\
\hline Table 3: Comparison of Anthropometric in Two Groups \\
Studied \\
\hline
\end{tabular}

\begin{tabular}{|c|c|c|c|}
\hline $\begin{array}{c}\text { SBP } \\
\text { (mmHg) }\end{array}$ & Group B & Group C & P value \\
\hline 0 min. & $125.34 \pm 7.83$ & $125.73 \pm 8.05$ & 0.852 \\
\hline 5 mins. & $125.87 \pm 9.18$ & $125.87 \pm 6.83$ & 1.000 \\
\hline 10 mins. & $125.70 \pm 9.08$ & $124.13 \pm 5.89$ & 0.431 \\
\hline 15 mins. & $122.93 \pm 8.12$ & $121.13 \pm 6.30$ & 0.341 \\
\hline 20 mins. & $121.53 \pm 9.08$ & $118.20 \pm 5.93$ & 0.098 \\
\hline 25 mins. & $121.13 \pm 9.92$ & $116.73 \pm 5.81$ & 0.040 \\
\hline 30 mins. & $118.17 \pm 9.78$ & $114.80 \pm 4.44$ & 0.092 \\
\hline \multicolumn{4}{|c|}{ Table 4: Comparison of SBP (mmHg) in } \\
Two Groups Studied \\
\hline
\end{tabular}

\begin{tabular}{|c|c|c|c|}
\hline $\begin{array}{c}\text { DBP } \\
\text { (mmHg) }\end{array}$ & Group B & Group C & P value \\
\hline 0 min. & $79.83 \pm 6.88$ & $79.93 \pm 6.86$ & 0.955 \\
\hline 5 mins & $78.77 \pm 8.19$ & $79.83 \pm 6.60$ & 0.581 \\
\hline 10 mins. & $78.37 \pm 6.47$ & $79.67 \pm 5.51$ & 0.406 \\
\hline 15 mins. & $77.90 \pm 6.01$ & $78.03 \pm 4.75$ & 0.924 \\
\hline 20 mins. & $76.47 \pm 5.26$ & $77.33 \pm 4.44$ & 0.493 \\
\hline 25 mins. & $77.70 \pm 5.35$ & $77.07 \pm 5.00$ & 0.638 \\
\hline 30 mins. & $75.57 \pm 4.74$ & $76.20 \pm 4.44$ & 0.595 \\
\hline \multicolumn{4}{|c|}{ Table 5: Comparison of DBP (mmHg) } \\
in Two Groups Studied \\
\hline
\end{tabular}

\begin{tabular}{|c|c|c|c|}
\hline $\begin{array}{c}\text { MAP } \\
\text { (mmHg) }\end{array}$ & Group B & Group C & P value \\
\hline 0 min. & $95.03 \pm 5.90$ & $95.20 \pm 5.84$ & 0.913 \\
\hline 5 mins. & $94.47 \pm 7.21$ & $95.18 \pm 5.25$ & 0.664 \\
\hline 10 mins. & $94.14 \pm 5.40$ & $94.49 \pm 4.21$ & 0.784 \\
\hline 15 mins. & $92.91 \pm 5.67$ & $92.40 \pm 4.19$ & 0.693 \\
\hline 20 mins. & $91.49 \pm 4.77$ & $90.96 \pm 4.09$ & 0.643 \\
\hline 25 mins. & $92.18 \pm 4.95$ & $90.29 \pm 3.51$ & 0.094 \\
\hline 30 mins. & $89.77 \pm 4.91$ & $89.07 \pm 3.87$ & 0.542 \\
\hline \multicolumn{4}{|c|}{ Table 6: Comparison of MAP (mmHg) } \\
in Two Groups Studied \\
\hline
\end{tabular}

\begin{tabular}{|c|c|c|c|}
\hline & Group B & Group C & $\begin{array}{c}\text { P } \\
\text { value }\end{array}$ \\
\hline $\begin{array}{c}\text { Sensory onset time } \\
\text { (min.) }\end{array}$ & $17.63 \pm 3.25$ & $7.20 \pm 1.95$ & $<0.001$ \\
\hline $\begin{array}{c}\text { Motor onset time } \\
\text { (min.) }\end{array}$ & $20.57 \pm 2.92$ & $9.87 \pm 2.60$ & $<0.001$ \\
\hline \multicolumn{3}{|c|}{ Table 7: Onset of Sensory and Motor Blockade } \\
\hline
\end{tabular}

\begin{tabular}{|c|c|c|c|}
\hline & Group B & Group C & $\begin{array}{c}\text { P } \\
\text { value }\end{array}$ \\
\hline $\begin{array}{c}\text { Duration of } \\
\text { Sensory } \\
\text { (DOSB) (min.) }\end{array}$ & $359.00 \pm 60.53$ & $552.67 \pm 32.05$ & $<0.001$ \\
\hline $\begin{array}{c}\text { Duration of } \\
\text { Motor Block } \\
\text { (DOMB) (min.) }\end{array}$ & $390.00 \pm 55.52$ & $597.33 \pm 27.91$ & $<0.001$ \\
\hline \multicolumn{2}{|c|}{} & & \\
\hline
\end{tabular}

Table 8: Duration of Sensory and Motor Block

\begin{tabular}{|c|c|c|c|}
\hline & Group B & Group C & $\begin{array}{c}\text { P } \\
\text { value }\end{array}$ \\
\hline $\begin{array}{c}\text { Duration of } \\
\text { Analgesia } \\
\text { (min.) }\end{array}$ & $361.67 \pm 59.77$ & $563.67 \pm 33.16$ & $<0.001$ \\
\hline \multicolumn{3}{|c|}{ Table 9: Duration of Analgesia } \\
\hline
\end{tabular}

\section{DISCUSSION}

The peripheral administration of appropriate drugs (Adjuncts) may have analgesic benefit and reduce systemic adverse effects. In an attempt to improve perioperative analgesia, a variety of adjuncts such as opioids, verapamil, neostigmine and tramadol have been administered concomitantly with local anaesthetics into the brachial plexus sheath.

\section{Onset of Sensory Blockade (Table 7)}

In our study, we observed that onset of sensory onset was earlier in study group of Clonidine having a mean value of $7.20 \pm 1.95$ mins. in comparison with Bupivacaine group having mean value of $17.63 \pm 3.25$ mins., which is statistically significant $(\mathrm{p}=<0.001)$. 
This observation well matches with study of Susmitha Chakraborthy, ${ }^{1}$ onset of sensory $6.2 \pm 0.78$ mins. and $8.7 \pm 1.01$ mins. in group $\mathrm{C}$ and group $\mathrm{B}$ respectively.

Similar observation was made by Gabriella Iohom, ${ }^{2}$ where the onset time of sensory block was much faster in group C, 21.3 \pm 7.2 mins. compared to that of group B (24.7 \pm 5.5 mins.).

Santvana Kohli, Manpreet Kaur 32013 conducted a study comparison of two different doses of clonidine added to bupivacaine. They concluded in their study higher doses of clonidine $(2 \mu \mathrm{g} / \mathrm{kg})$ in brachial plexus block hastens the onset of sensory blocks. Sensory onset of time was $9.9 \pm 4.1$ mins.

\section{Onset of Motor Blockade (Table 7)}

In our study, we observed that onset of motor block was earlier in study group of Clonidine having the mean value of $9.87 \pm 2.60$ mins. and in comparison the Bupivacaine group had a mean value of $20.57 \pm 2.92$ mins., which is statistically significant $(\mathrm{p}=<0.001)$.

This observation matches well with the study conducted by Susmitha Chakraborthy ${ }^{1}$ who had earlier onset of motor blockade in group C compared to group B, $10.6 \pm 1.36$ mins. and $18.1 \pm 1.35$ mins. respectively.

Daniel M. Popping ${ }^{4}$ had contrasting result as time for onset of motor block, quantified by using the Bromage scale. In control group, mean onset time of motor block was 18.3 mins. and Clonidine had no significant impact on onset time.

Santvana Kohli, Manpreet Kaur ${ }^{3}$ concluded in their study higher doses of clonidine $(2 \mu \mathrm{g} / \mathrm{kg})$ in brachial plexus block hastens the onset of motor blocks. Motor onset of time was 13.2 \pm 6.7 mins.

\section{Duration of Sensory Blockade (Table 8)}

The duration of sensory blockade, in our study was $552.67 \pm 32.05$ mins. with Bupivacaine plus Clonidine group and $359.00 \pm 60.53$ mins. for Bupivacaine group, which is statistically significant ( $\mathrm{p}=<0.001$ ).

Gabriella Iohom $^{2}$ in his study, found that the duration of sensory block was longer in Bupivacaine plus Clonidine group compared with placebo $275 \pm 75$ versus $163 \pm 57 ; \mathrm{P}=0.04$, these observations were similar to our study.

In a study conducted by Henri Iskandar, 5 the median sensory block was 235 mins. (195-250) in the Bupivacaine plus Clonidine group compared with 150 mins. (135-160) in the control group.

Giovanni Cucchiaro ${ }^{6}$ et al, in his study on children using $0.25 \%$ Bupivacaine found significant prolongation of duration of sensory block with Bupivacaine plus Clonidine group 1140 mins. compared to control 840 mins.

\section{Duration of Motor Blockade (Table 8)}

In our study, the duration of motor blockade was found to be $597.33 \pm 27.91$ mins. in Bupivacaine plus clonidine group compared to $390.00 \pm 55.52$ mins. in Bupivacaine group and this difference was statistically significant $(\mathrm{p}=0.001)$.

In the meta-analysis conducted by Daniel M. Popping, ${ }^{4}$ the average duration of motor block was 405 mins. (range 122728 ) in control group. Clonidine significantly prolonged the duration of block to 546 mins.

According to study conducted by Wolfgang Erlacher ${ }^{7}$ et al, the duration of blockade in the Bupivacaine group was 728 mins. in control and in comparison Bupivacaine plus Clonidine group had 972 mins., which are matching well with our study.

\section{Duration of Analgesia (Table 9)}

The mean time from onset of block to request of analgesia is taken as total duration of analgesia. It was $563.67 \pm 33.16$ mins. Bupivacaine plus Clonidine group and $361.67 \pm 59.77$ in Bupivacaine group which is statistically significant $p=<0.001$.

According to Murphy ${ }^{8}$ et al, Clonidine provided an analgesic effect that lasted as long as 492 mins. which is twice the duration of placebo 260 mins.

In Daniel M. Popping ${ }^{4}$ study, the duration of postoperative analgesia for control group was 461 mins., whereas Clonidine significantly increased the duration 584 mins.

Santvana Kohli, Manpreet Kaur ${ }^{3}$ concluded in their study higher doses of clonidine $(2 \mu \mathrm{g} / \mathrm{kg})$ in brachial plexus block prolongs duration of analgesia. Total duration of analgesia was $21 \pm 2.96 \mathrm{~h}$, which well matches with our study.

\section{CONCLUSION}

Addition of Clonidine to Bupivacaine solution for brachial plexus block can modify the action of local anaesthetic solution by its local action. The dosage $2 \mu / \mathrm{kg}$ body weight used in our study significantly increased the duration of analgesia and muscle relaxation. There were no clinically significant side effects noticed.

Hence, Clonidine can form an useful adjuvant for Bupivacaine when used for brachial plexus block.

\section{REFERENCES}

1. Chakraborty S, Chakrabarti J, Mandal MC, et al. Effect of clonidine as adjuvant in bupivacaine-induced supraclavicular brachial plexus block: a randomized controlled trial. Indian J Pharmacol 2010;42(2):74-7.

2. Iohom G, Machmachi A, Diarra DP, et al. The effects of clonidine added to mepivacaine for paronychia surgery under axillary brachial plexus block. Anesth Analg 2005;100(4):1179-83.

3. Kohli S, Kaur M, Sahoo S, et al. Brachial plexus block: comparison of two different doses of clonidine added to bupivacaine. J Anaesthesiol Clin Pharmacol 2013;29(4):491-5.

4. Popping DM, Elia N, Marret E, et al. Clonidine as an adjuvant to local anesthetics for peripheral nerve and plexus blocks: a meta-analysis of randomized trials. Anesthesiology 2009;111(2):406-15.

5. Iskandar $\mathrm{H}$, Benard A, Ruel-Raymond J, et al. The analgesic effect of interscalene block using clonidine as an analgesic for shoulder arthroscopy. Anesth Analg 2003;96(1): 260-2.

6. Cucchiaro G, Ganesh A. The effects of clonidine on postoperative analgesia after peripheral nerve blockade in children. Anesth Analg 2007;104(3):532-7.

7. Erlacher $\mathrm{W}$, Schuschnig $\mathrm{C}$, Koinig $\mathrm{H}$, et al. Clonidine as adjuvant for mepivacaine, ropivacaine and bupivacaine in axillary, perivascular brachial plexus block. Canadian J Anesth 2001;48(6):522-5.

8. Murphy DB, McCartney CJ, Chan VW. Novel analgesic adjuncts for brachial plexus block: a systematic review. Anesth Analg 2000;90(5):1122-8. 